\title{
The association of vaccination and the incidence of new cases of COVID-19 among health care workers, December 16, 2020 through May 4, 2021
}

Fadi Al Akhrass ( $\square$ fadi.akhrass@pikevillehospital.org )

Pikeville Medical Center

Nina Reynolds

Pikeville Medical Center

Christina Al Akhrass

Pikeville Medical Center

James Dawahare

Pikeville Medical Center

Rishi Raj

Pikeville Medical Center

Gregory Green

University of Pikeville

Richard Hom

New England College of Optometry

\section{Research Article}

Keywords: COVID-19, SARS-CoV-2, BNT162b2 (BioNTech-Pfizer), mRNA-1273 mRNA (Moderna), healthcare workers, vaccine effectiveness

Posted Date: June 11th, 2021

DOl: https://doi.org/10.21203/rs.3.rs-612401/v1

License: (c) (1) This work is licensed under a Creative Commons Attribution 4.0 International License. Read Full License 


\section{Abstract}

Severe acute respiratory syndrome coronavirus 2 (SARS-CoV-2) is the virus that causes the coronavirus disease 2019 (COVID-19). This highly transmissible and pathogenic virus has caused a significant threat to health care workers (HCW) as well as human health and public safety. Several studies have shown the value and effectiveness of messenger ribonucleic acid (mRNA) vaccines (mRNA) protecting HCWs from symptomatic or asymptomatic SARS-CoV-2 infections. New research is needed to demonstrate the effectiveness of vaccines where the follow-up periods are more extended than prior research. This study uses a "real-world" cohort of HCWs and provides insight into the effectiveness of the mRNA vaccines against HCWs with symptomatic SARS-CoV-2 infection. Symptomatic SARS-CoV-2 infection occurred in 5 fully vaccinated HCWs and 124 unvaccinated HCWs (incidence rate, 4.14 vs. 95.53 per 100000 persondays, respectively, incidence risk ratio (IRR), 0.0433 [95\% Cl, 0.018-0.1]). Receipt of the authorized mRNA vaccines was associated with a significantly lower incidence of symptomatic SARS-CoV-2 infection for a median follow-up of 139 days. Ways to enhance complete vaccination and, subsequently, optimal immunity is required to lift masking restrictions in the health care settings.

\section{Introduction}

The dynamics of COVID-19 are unprecedented, and it has become clear that the response to COVID-19 is more like a marathon than a sprint. Three COVID-19 vaccines are currently authorized and recommended for use in the United States, including the one-dose adenovirus-vector Johnson and Johnson/Janssen and the two-dose mRNA Moderna and Pfizer/BioNTech vaccines. The U.S COVID-19 vaccination program began on December 14,2020 . As of June $3,2021,41.2 \%$ of the total population in the U.S. was fully vaccinated and $50.9 \%$ received at least one vaccine dose [1]. In general, people are considered fully vaccinated two weeks after their second dose in a 2-dose series, such as the Pfizer or Moderna vaccines, or two weeks after a single-dose vaccine, such as Johnson \& Johnson's Janssen vaccine [2]. Data on mRNA vaccine effectiveness for HCWs, who are frequently at risk of exposure to SARS-CoV-2, has been consistent with the results from the phase 3 randomized clinical trials of the mRNA vaccines, which showed efficacy against symptomatic SARS-CoV-2 infection around 95\% [3-12]. Authorized vaccines are not $100 \%$ effective at preventing symptomatic and asymptomatic infections, but they are effective, safe and crucial tools to control the pandemic. The risk of SARS-CoV-2 vaccine breakthrough infections after full vaccination is rare and estimated to be $0.01 \%(10,262 / 101,000,000)[13] .64 \%$ of these cases involved a SARS-CoV-2 variant of concern (VOC). These variants included B.1.1.7 (UK) in 56\% of breakthrough cases, B.1.427 (California) in 29\%, P.1 (Brazil) in 29\%, B.1.429 in 25\% (California), and B.1.351 (South Africa) in $13 \%$ [13].

On December 16, 2020, a large-scale campaign was launched at Pikeville Medical Center, in close collaboration with the State of Kentucky and the Pike County Public Health Departments, to vaccinate its HCWs, along with individuals at increased risk of COVID-19 complications and death. Both mRNA vaccines, Pfizer/BioNTech COVID-19 (BNT162b2) vaccine (Pfizer, Inc: Philadelphia, Pennsylvania) and Moderna (mRNA-1273) vaccine (Moderna TX, Inc; Cambridge, Massachusetts) were administered upon 
State-derived allocations. Concurrently with the vaccination campaign, the number of new COVID-19 cases surged in Kentucky, with the highest daily new SARS-CoV-2 cases was 5,742 reported on January 6, 2021 (Fig. 1), [14] possibly due to the spread of the B.1.1.7 SARS-CoV-2 variant, which has overtaken the pandemic in the U.S. [15]. This study was conducted to assess the effectiveness of vaccination with the two authorized mRNA vaccines against symptomatic SARS-CoV-2 infections in HCWs over almost five months and add to the rapidly evolving body of evidence in this domain.

\section{Methods}

\section{Study Design}

This retrospective cohort study examined the association between vaccination with the BNT162b2 and m-RNA-1273 vaccines and the incidence of new cases of symptomatic SARS-CoV-2 infections among HCWs. The study was conducted at the Pikeville Medical Center, a tertiary medical center that employs over 3,000 HCWs. All HCWs were eligible to receive the vaccine from the first day of the vaccination campaign on December 16, 2020, and throughout the study period until May 4, 2021 (Figure 2). Employment status, personal demographics, vaccination dates, and SARS-COV-2 molecular test results were retrieved from the Employee Health information system database. Participants who contracted SARS-CoV-2 infection before study enrollment were excluded. All employees were screened daily with an electronic "Fast Pass," where the employees completed a questionnaire. Those who did not pass the "Fast Pass" were sent directly to NP-SARS-CoV-2 testing. Polymerase chain reaction (PCR) confirmed all positive lateral-flow antigen tests. Participants infected with SARS-CoV-2 were defined as symptomatic if they had any of the following: temperature greater than $37.6^{\circ} \mathrm{C}\left(100.4{ }^{\circ} \mathrm{F}\right)$, headache, sore throat, cough, dyspnea, rhinorrhea, diarrhea, myalgia, or loss of sense of taste or smell. All HCWs who had laboratoryconfirmed COVID-19 by PCR were isolated under the Centers for Disease Control and Prevention (CDC) protocols [16]. Frequent asymptomatic respiratory PCR or antigen or serum SARS-CoV-2 antibody testing was not performed to evaluate the silent transmission rate. Furthermore, information on VOC was not available. We used the sample date of a positive PCR result as the event date, which might have introduced some misclassification of vaccination status relative to infection. Days 0 through 13 after the first dose were excluded from the final effectiveness analysis. All records were de-identified before analysis, and Ethics approval was obtained from the institutional review board and a waiver of written informed consent.

\section{Group Assignment and Definition of the Follow-up Period}

Health care workers who received at least one vaccine dose between December 16, 2020, and May 4 , 2021 , were assigned to the vaccinated group. The unvaccinated control group was composed of HCWs who did not receive any vaccine doses during this period. The follow-up period for each "vaccinated" HCW was defined as starting on the day of receiving the first vaccine dose and ending either on May 4, 2021 or at the termination date of employment if it occurred before May 4, 2021. The follow-up period for each "unvaccinated" HCW was defined as starting either on December 16,2020 , or the date of hiring if it 
happened after December 16, 2020, and before May 4, 2021, and ending either on May 4, 2021, or at the termination date of employment if occurred before May 4, 2021. All participants, vaccinated and unvaccinated, were censored at the first positive PCR test result. The number of risk days for each employee was defined as any day in the appropriate follow-up period. During this timeframe, the 7-day average of new SARS-CoV-2 infections, dropped significantly over time in the state of Kentucky (Figure 1)

\section{Definitions}

Participants were considered fully vaccinated after 14 or more days ( $\geq 14$ days) after the second dose of the mRNA vaccine (Pfizer/BioNTech or Moderna) [2[. Partial vaccination occurred 14 or more days ( $\geq 14$ days) from the first vaccine and before the second dose or to the end of the follow-up period if the second dose was not administered.

\section{Study Outcomes and statistical analysis}

The primary outcome was the effectiveness of mRNA vaccines against HCWs with symptomatic SARSCoV-2 infection when fully vaccinated and no prior documented prior infection. These HCWs were compared with unvaccinated HCW for a follow-up period of twenty weeks. The secondary outcome was the effectiveness of partial vaccination with symptomatic SARS-CoV-2 infection in comparison with unvaccinated HCWs. The reference group was the incidence rate of COVID-19 among unvaccinated HCWs. We calculated the incidence rate ratio (IRR) and exact 95\% confidence interval (Cl) and defined vaccine effectiveness as 1-IRR [17]. The groups were compared using $t$-tests for normally distributed continuous variables and $\chi^{2}$ tests for categorical variables. All reported tests were 2 -sided, and a $P$ value of less than .05 was considered significant. All statistical analyses were performed using R software version 4.0.3 (R Foundation for Statistical Computing).

\section{Results}

A total of 2904 HCWs without prior documented SARS-CoV-2 infection (median [S.D.] age, 38 [12] years; 2134 [73.48 \%] women) comprised the retrospective cohort. Of this cohort, $1513 \mathrm{HCWs}(51.10 \%)$ received at least 1 dose of the Pfizer/BioNTech (BNT162b2) or Moderna (mRNA-1273) vaccine, 1473 (50.72\%) received 2 doses, and 1391 (47.90\%) were not vaccinated. For the recipients of 2 doses of the Pfizer/BioNTech vaccine, the median days between doses was 21 (IQR, 21-21); For Moderna (mRNA1273), the median days between doses was 28 (IQR, 28-28). The median follow-up was 139 days (Dec 16, 2020 to May 4, 2021) (Vaccinated: mean days $=116.24, S D=33.36, I Q R=113-137$; Unvaccinated: mean days $=106.83, S D=46.93, I Q R=19-139)$. The baseline characteristics of the participants appear in Table 1. Vaccinated HCWs were older compared with unvaccinated participants (median age, 42 vs 33 years, respectively; $P<.001$ ). The estimated work-related risk of exposure to SARS-CoV-2 was interestingly similar in providers between the 2 groups. A total of 256 PCR-confirmed cases of symptomatic SARSCoV-2 infection were documented during the study period, with only 46 cases documented in the vaccinated group (Fig. 3). Symptomatic SARS-CoV-2 infection was detected in $46 \mathrm{HCW}$ who received at 
least one vaccine dose and 186 unvaccinated HCWs. For the primary outcome analysis, the incidence rate of symptomatic SARS-CoV-2 infection was 4.14 vs. 95.53 per 100000 person-days in the fully vaccinated and unvaccinated cohorts, respectively, corresponding with an IRR of $0.0433(95 \% \mathrm{Cl}, 0.018$ 0.1 ; Tables $2 \& 3)$. 
Table 1

Baseline characteristics of study participants

\begin{tabular}{|c|c|c|c|}
\hline Variable & Vaccinated & Unvaccinated & $\begin{array}{l}\mathrm{P} \text { - } \\
\text { value }\end{array}$ \\
\hline No. of participants & 1513 & 1391 & $\begin{array}{l}<.001 \\
0.00\end{array}$ \\
\hline Received 2 doses of vaccine, No. (\%) & $1473(97.36)$ & 0 & \\
\hline Age, median [SD], y & 42 [12.09] & 33 [11.65] & $\begin{array}{l}<.001 \\
0.00\end{array}$ \\
\hline \multicolumn{4}{|l|}{ Age group, №. (\%) } \\
\hline$\leq 39 y$ & $656(43.36)$ & $925(66.50)$ & $\begin{array}{l}< \\
0.001\end{array}$ \\
\hline $40-59$ y & $726(47.98)$ & $422(30.34)$ & $\begin{array}{l}<.001 \\
0.00\end{array}$ \\
\hline$\geq 60 y$ & $131(8.66)$ & $44(3.16)$ & $\begin{array}{l}< \\
0.001\end{array}$ \\
\hline \multicolumn{4}{|l|}{ Sex, No. (\%) } \\
\hline Female, No (\%) & $1088(71.91)$ & $1046(75.20)$ & $\begin{array}{l}<.001 \\
0.00\end{array}$ \\
\hline Male, No (\%) & $425(28.09)$ & $320(23.01)$ & $\dot{c}_{0.001}$ \\
\hline \multicolumn{4}{|l|}{ Employment sector, No. (\%) } \\
\hline Administration $^{\mathrm{a}}$ & $517(34.17)$ & $426(30.63)$ & $\begin{array}{l}<.001 \\
0.00\end{array}$ \\
\hline Providers ${ }^{\mathrm{b}}$ & $187(12.36)$ & $68(4.89)$ & 1 \\
\hline Nursing ${ }^{c}$ & $396(26.17)$ & $530(38.10)$ & $\begin{array}{l}< \\
0.001\end{array}$ \\
\hline Other health professions ${ }^{d}$ & $413(27.30)$ & $367(26.38)$ & $\dot{0.001}$ \\
\hline
\end{tabular}

Abbreviations: IQR, interquartile range; S.D., standard deviation

${ }^{a}$ No direct patient contact

${ }^{b}$ Included doctors, nurse practitioners, and physician assistants

'Included nurse aids, registered nurses, and licensed practical nurses

dIncluded rehabilitation, speech, and respiratory therapists, phlebotomists, and other paramedical staff. 


\begin{tabular}{|c|c|c|c|}
\hline Variable & Vaccinated & Unvaccinated & $\begin{array}{l}\mathrm{P}- \\
\text { value }\end{array}$ \\
\hline Active COVID-19, No. (\%) & $46(3.04 \%)$ & $164(11.79 \%)$ & $\dot{0} 001$ \\
\hline Mean follow-up time, days [SD; IQR] & $\begin{array}{l}116.24[33.37 ; 113- \\
137]\end{array}$ & $\begin{array}{l}106.83[46.94 ; 69- \\
139]\end{array}$ & \\
\hline $\begin{array}{l}\text { No. hospitalizations for severe COVID- } \\
19\end{array}$ & 0 & 5 & \\
\hline Death & 0 & 0 & \\
\hline \multicolumn{4}{|c|}{ Abbreviations: IQR, interquartile range; S.D., standard deviation } \\
\hline \multicolumn{4}{|l|}{ aNo direct patient contact } \\
\hline \multicolumn{4}{|c|}{ b/ncluded doctors, nurse practitioners, and physician assistants } \\
\hline \multicolumn{4}{|c|}{ Included nurse aids, registered nurses, and licensed practical nurses } \\
\hline
\end{tabular}


Table 2

Observed Incidence Rate of Symptomatic SARS-CoV-2 Infection in the vaccinated group ${ }^{a}$

\begin{tabular}{|c|c|c|c|c|c|}
\hline $\begin{array}{l}\text { Vaccination } \\
\text { status }\end{array}$ & $\begin{array}{l}\text { No. } \\
\text { COVID-19 } \\
\text { cases }\end{array}$ & $\begin{array}{l}\text { Surveillance } \\
\text { time, person- } \\
\text { days }\end{array}$ & $\begin{array}{l}\text { Incidence rate per } \\
100,000 \text { person- } \\
\text { days }\end{array}$ & $\begin{array}{l}\text { Incidence relative } \\
\text { ratio (IRR) (95\% Cl) }\end{array}$ & $\begin{array}{l}P \\
\text { value }\end{array}$ \\
\hline $\begin{array}{l}\text { Fully } \\
\text { vaccinated }^{\mathrm{b}}\end{array}$ & 5 & 120,852 & 4.14 & $0.0433(0.018,0.1)$ & $\stackrel{<}{0.001}$ \\
\hline $\begin{array}{l}\text { Partially } \\
\text { vaccinated }^{c}\end{array}$ & 13 & 34371 & 37.82 & $0.3959(0.224,0.7)$ & $<.001$ \\
\hline Unvaccinated & 124 & 129799 & 95.53 & & \\
\hline \multicolumn{6}{|c|}{$\begin{array}{l}\text { aWhen estimating incidence of symptomatic SARS-CoV- } 2 \text { infections, follow-up was ceased on the day } \\
\text { of COVID- } 19 \text { case confirmation, the termination date of employment, or the end of follow-up on May } \\
4,2021 \text {. Participants with fewer than } 14 \text { days }(<14 \mathrm{~d}) \text { of follow-up or who contracted SARS-CoV-2 } \\
\text { less than } 14 \text { days after the first vaccine dose were excluded in this analysis }\end{array}$} \\
\hline \multicolumn{6}{|c|}{$\begin{array}{l}\text { bIncluded those with data equal or longer than } 14 \text { days ( } \geq 14 \mathrm{~d} \text { ) after the second vaccine dose to the } \\
\text { end of follow-up }\end{array}$} \\
\hline \multicolumn{6}{|c|}{$\begin{array}{l}\text { Cncluded those with data equal or longer than } 14 \text { days }(\geq 14 \mathrm{~d}) \text { from the first vaccine dose and fewer } \\
\text { than } 14 \text { days after the second dose if it happened, otherwise to the end of the follow-up. }\end{array}$} \\
\hline \multicolumn{6}{|c|}{$\begin{array}{l}\text { The incidence rates were defined for each of the two groups as the number of positive SARS-CoV-2 } \\
\text { cases divided by the cumulative follow-up time of the HCWs in the group within the examined time } \\
\text { frame }\end{array}$} \\
\hline \multicolumn{6}{|c|}{$\begin{array}{l}\text { The incidence rate ratio (IRR) was computed directly from the incidence rates of the two groups as } \\
\text { simply the ratios of incidence rates between the vaccinated (fully and partially) group and } \\
\text { unvaccinated group. }\end{array}$} \\
\hline
\end{tabular}

Table 3. Characteristics of the five HCWs with breakthrough COVID-19 cases. 


\begin{tabular}{|c|c|c|c|c|c|}
\hline $\begin{array}{l}\text { Breakthrough } \\
\text { COVID-19 cases }^{a}\end{array}$ & $\begin{array}{l}\text { Age, } \\
y\end{array}$ & Sex & Comorbidities & Symptoms & Hospitalization \\
\hline Case 1 & 33 & Female & $\begin{array}{l}\text { BMl>30, HTN, } \\
\text { hypothyroidism, DM, } \\
\text { asthma }\end{array}$ & Cough & No \\
\hline Case 2 & 37 & Female & Depression & $\begin{array}{l}\text { Rhinorrhea, } \\
\text { headache }\end{array}$ & No \\
\hline Case 3 & 24 & Female & None & $\begin{array}{l}\text { Rhinorrhea, } \\
\text { headache }\end{array}$ & No \\
\hline Case 4 & 59 & Female & $\begin{array}{l}\text { HTN, hypothyroidism, } \\
\text { GERD, DM, AFib }\end{array}$ & $\begin{array}{l}\text { Unknown, most } \\
\text { likely } \\
\text { asymptomatic }\end{array}$ & No \\
\hline Case 5 & 39 & Female & Cystic fibrosis & Rhinorrhea & No \\
\hline
\end{tabular}

Abbreviations: AFib, atrial fibrillation; DM, diabetes mellitus; GERD, gastro-esophageal reflux disease; HTN, hypertension

aBreakthrough COVID-19 cases are defined as the occurrence of symptomatic or asymptomatic SARSCoV-2 infection after 14 days from receiving 2 doses of the messenger RNA vaccines (Pfizer/BioNTech and Moderna) and 1 dose of the adenovirus viral-vector Johnson and Johnson. Only 5 cases were detected, however that number could be underestimated as regular testing was not performed to unveil asymptomatic cases. All these breakthrough cases received the Pfizer/BioNTech vaccine.

\section{Discussion}

The COVID-19 has placed a massive physical and mental health burden on HCWs. Vaccines have shown an early impact on the "domino effect" of the SARS-CoV-2 infection. Several studies provided strong short-term evidence that vaccinating $\mathrm{HCWs}$ can substantially reduce symptomatic and asymptomatic SARS-CoV-2 infection and, therefore, might help to reduce transmission of infection in the healthcare settings [5-12]. In this retrospective cohort study, vaccination with two doses of the authorized available mRNA vaccines was associated with a significantly lower incidence rate for symptomatic SARS-CoV-2 infection in HCWs. The IRR for the fully vaccinated participants was 0.043 for symptomatic infection, corresponding to the estimated vaccine effectiveness of $95.7 \%$. The results of this study are in full agreement with the impact of the mRNA vaccines on COVID-19 in randomized control trials [3.4]. To achieve optimal immunity, completing the series of two doses of the mRNA vaccines is required in individuals without prior exposure to SARS-CoV-2 infection. Vaccination is not synonymous with immunity and subsequently does not wholly eliminate infection risk, especially in the healthcare setting. The silent spread of SARS-CoV-2 infection was a significant driver of the COVID-19 pandemic [18-20]. Asymptomatic infection accounted for $27 \%$ of the reported breakthrough SARS-CoV-2 infections in the United States, and this number is an underestimate [13]. Furthermore, COVID-19 vaccine skepticism was 
present in our study. In these cases, HCWs used appropriate personal protective equipment, social distancing, and frequent hand hygiene to maintain a safe medical practice. This practice should continue until the prevalence of SARS-CoV-2 has fallen to much lower levels to safeguard the healthcare setting.

\section{Strengths}

The data on study participants were collected in real time with a relatively longer follow-up time than prior studies. Furthermore, the vaccinated and unvaccinated cohorts are similar in size and composition.

\section{Limitations}

This study has several limitations. First, the inherent characteristics of a single-center, retrospective observational study might limit the generalizability of the findings. Second, the vaccinated and unvaccinated cohorts differed in some individual characteristics. Unvaccinated HCWs were younger. Third, HCWs were screened daily with an electronic "Fast Pass," and there may be a bias concerning the decision of "feeling ill" dependent on the vaccination status. Vaccinated recipients may be less likely to seek testing for minor symptoms, which may falsely increase vaccination effectiveness. Furthermore, there may also be a bias concerning overall behavior for mitigation measures between vaccinated and unvaccinated HCWs. Fourth, the study did not look at a regular collection of respiratory specimens in the participants irrespective of symptoms to see the impact on silent transmission, not just illness prevention. Comparison of disease severity and viral load or cycle threshold (Ct) value of PCR tests between vaccinated and unvaccinated HCWs is another objective that may need to be investigated. Fifth, we presume that most COVID-19 cases were community-related, as the hospital's Infection Prevention department could not identify any nosocomial source. The hospital is implementing robust masking and social distancing rules. However, the possibility of hospital-acquired infections cannot be excluded, as these HCWs are caring and interacting with active cases of COVID-19.

\section{Conclusions}

Among HCWs at a single-center in Pikeville, Kentucky, the receipt of the BNT162b2 and mRNA-1273 vaccines compared with no vaccine was associated with a significantly lower incidence of symptomatic SARS-CoV-2 infection for twenty weeks following vaccination. The earlier HCWs achieve herd immunity; the quicker mitigation measures can be lifted in the health care settings. Rigorous genetic surveillance is crucial to determine if breakthrough cases will increase with time and with which VOC, to evaluate vaccines that are most effective against future variants.

\section{Declarations}

\section{Author Contributions:}


Acquisition, analysis, or interpretation of data: Gregory Green and Fadi Al Akhrass

Drafting of manuscript. All authors contributed

Administrative, technical, or material support: Fadi Al Akhrass

Supervision: Fadi Al Akhrass

\section{No conflict of interest}

\section{Disclaimer:}

Opinions, interpretations, conclusions, and recommendations are those of the authors and are not necessarily endorsed by the Pikeville Medical Center, the University of Pikeville, or the New England College of Optometry.

\section{References}

1-Centers for Disease Control and Prevention. Coronavirus disease 2019 (COVID19).

https://covid.cdc.gov/covid-data-tracker/\#vaccinations. Accessed on June 3, 2021.

2-Centers for Disease Control and Prevention. Coronavirus disease 2019 (COVID19). https://www.cdc.gov/vaccines/covid-19/health-departments/breakthrough-cases.html. Accessed on May 18, 2021.

3-Polack FP, Thomas SJ, Kitchin N, et al; C4591001 Clinical Trial Group. Safety and efficacy of the BNT162b2 mRNA Covid-19 vaccine. N Engl J Med. 2020;383(27):2603-2615. doi:10.1056/NEJMoa2034577

4-Baden LR, El Sahly HM, Essink B, et al. Efficacy and Safety of the mRNA-1273 SARS-CoV-2 Vaccine. N Engl J Med. 2021; 384:403-416. DOI: 10.1056/NEJMoa2035389

5-Thompson MG, Burgess JL, Naleway AL, et al. Interim Estimates of Vaccine Effectiveness of BNT162b2 and mRNA-1273 COVID-19 Vaccines in Preventing SARS-CoV-2 Infection Among Health Care Personnel, First Responders, and Other Essential and Frontline Workers - Eight U.S. Locations, December 2020March 2021. MMWR. 2021:70(13);495-500.

6-Angel Y, Spitzer A, Henig O, et al. Association Between Vaccination with BNT162b2 and Incidence of Symptomatic and Asymptomatic SARS-CoV-2 Infections Among Health Care Workers. JAMA. Published online May 06, 2021. doi:10.1001/jama.2021.7152

7-Benenson S, Oster Y, Cohen MJ, Nir-Paz R. BNT162b2 mRNA Covid-19 vaccine effectiveness among health care workers. N Engl J Med. Published online March 23, 2021. doi:10.1056/NEJMc2101951 
8-Keehner J, Horton LE, Pfeffer MA, et al. SARS-CoV-2 Infection after Vaccination in Health Care Workers in California. N Engl J Med. 2021; 384:1774-1775. DOI: 10.1056/NEJMc2101927

9-Daniel W, Nivet M, Warner J, Podolsky DK. Early Evidence of the Effect of SARS-CoV-2 Vaccine at One Medical Center. N Engl J Med. Published on line March 23, 2021. DOI: 10.1056/NEJMc2102153

10-Amit S, Regev-Yochay G, Afek A, Kreiss Y, Leshem E. Early rate reductions of SARS-CoV-2 infection and COVID-19 in BNT162b2 vaccine recipients. Lancet. 2021;397(10277):875-877. doi:10.1016/S01406736(21)00448-7

11-Hall VJ, Foulkes S, Saei A, et al. COVID-19 vaccine coverage in healthcare workers in England and effectiveness of BNT162b2 mRNA vaccine against infection (SIREN): a prospective, multicentre, cohort study. Lancet. 2021;397:1725-35. DOl:https://doi.org/10.1016/S0140-6736(21)00790-X.

12-Swift MD, Breeher LE, Tande AJ, et al. Effectiveness of mRNA COVID-19 vaccines against SARS-CoV-2 infection in a cohort of healthcare personnel, Clin Infect Dis. 2021; ciab361, https://doi.org/10.1093/cid/ciab361

13- Birhane M, Bressler S, Chang G, et al. COVID-19 Vaccine Breakthrough Infections Reported to CDC United States, January 1-April 30, 2021. MMWR. 2021:70(21);792-973. DOI:

http://dx.doi.org/10.15585/mmwr.mm7021e3.

14-Centers for Disease Control and Prevention. Coronavirus disease 2019

(COVID19). https://chfs.ky.gov/Pages/cvdaily.aspx. Accessed on May 18, 2021.

15-Centers for Disease Control and Prevention. Coronavirus disease 2019 (COVID19). https://covid.cdc.gov/covid-data-tracker/\#variant-proportions. Accessed May 18, 2021.

16-Centers for Disease Control and Prevention. Coronavirus disease 2019 (COVID19).

https://www.cdc.gov/coronavirus/2019-ncov/hcp/duration-isolation.html. Accessed May 28, 2021.

17-Chu H, Halloran ME. Bayesian estimation of vaccine efficacy. Clin Trials. 2004;1(3):306-14. doi.org/10.1191/1740774504cn025oa

18-Singanayagam A, Patel $M$, Charlett $A$, et al. Duration of infectiousness and correlation with RT-PCR cycle threshold values in cases of COVID-19, England, January to May 2020. Euro Surveill. 2020;25(32):1-5. doi:10.2807/1560-7917.ES.2020.25.32.2001483

19-Lee S, Kim T, Lee E, et al. Clinical course and molecular viral shedding among asymptomatic and symptomatic patients with SARS-CoV-2 Infection in a community treatment center in the Republic of Korea. JAMA Intern Med. 2020;180(11):1447-1452. doi:10.1001/jamainternmed.2020.3862

20-Oran DP, Topol EJ. Prevalence of asymptomatic SARS-CoV-2 infection: a narrative review. Ann Intern Med. 2020;173(5):362-367. doi:10.7326/M20-3012 
Figures

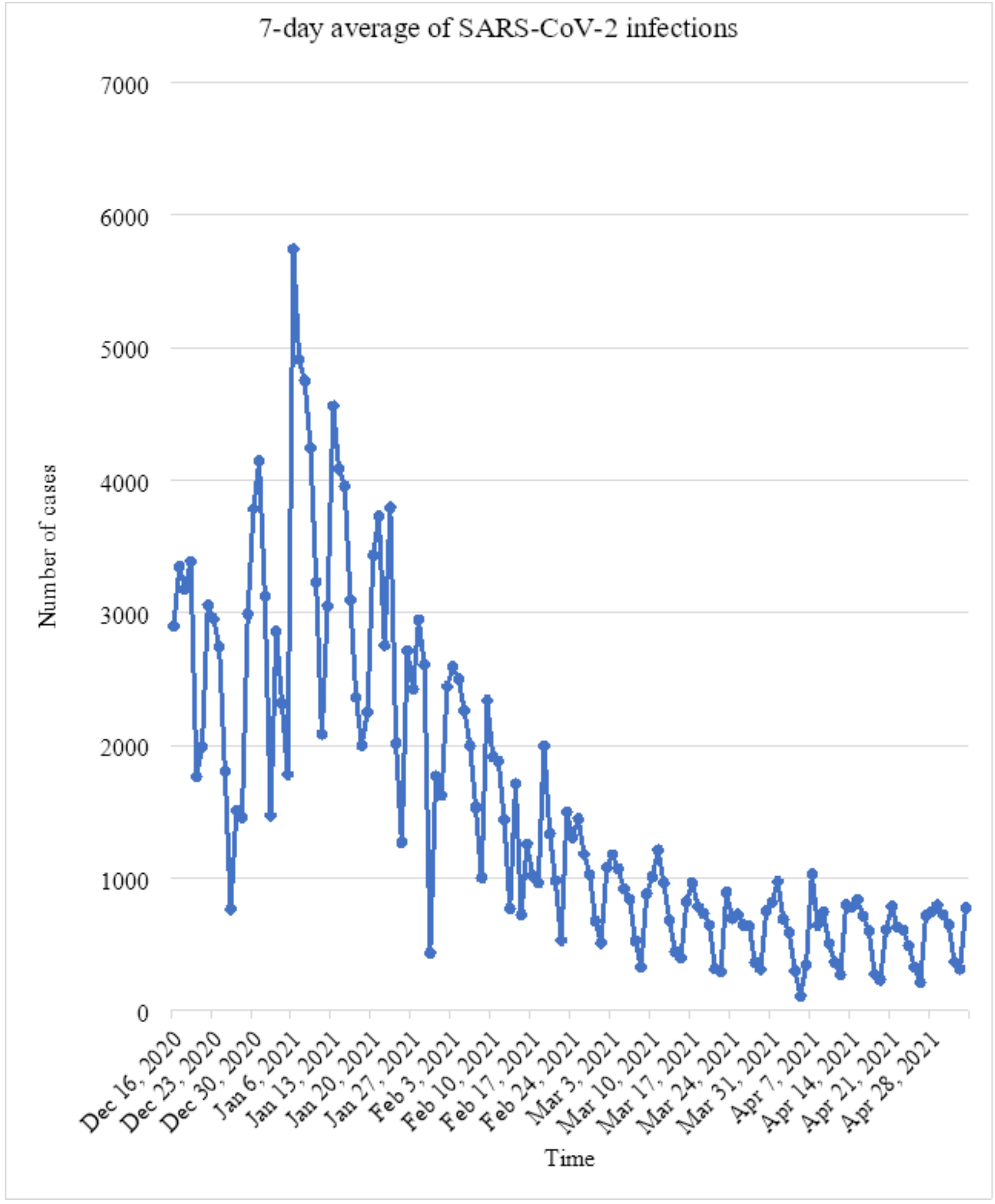

Figure 1

The 7-day average of new cases of SARS-CoV-2 infections in Kentucky, December 16, 2020 through May 4, 2021. 


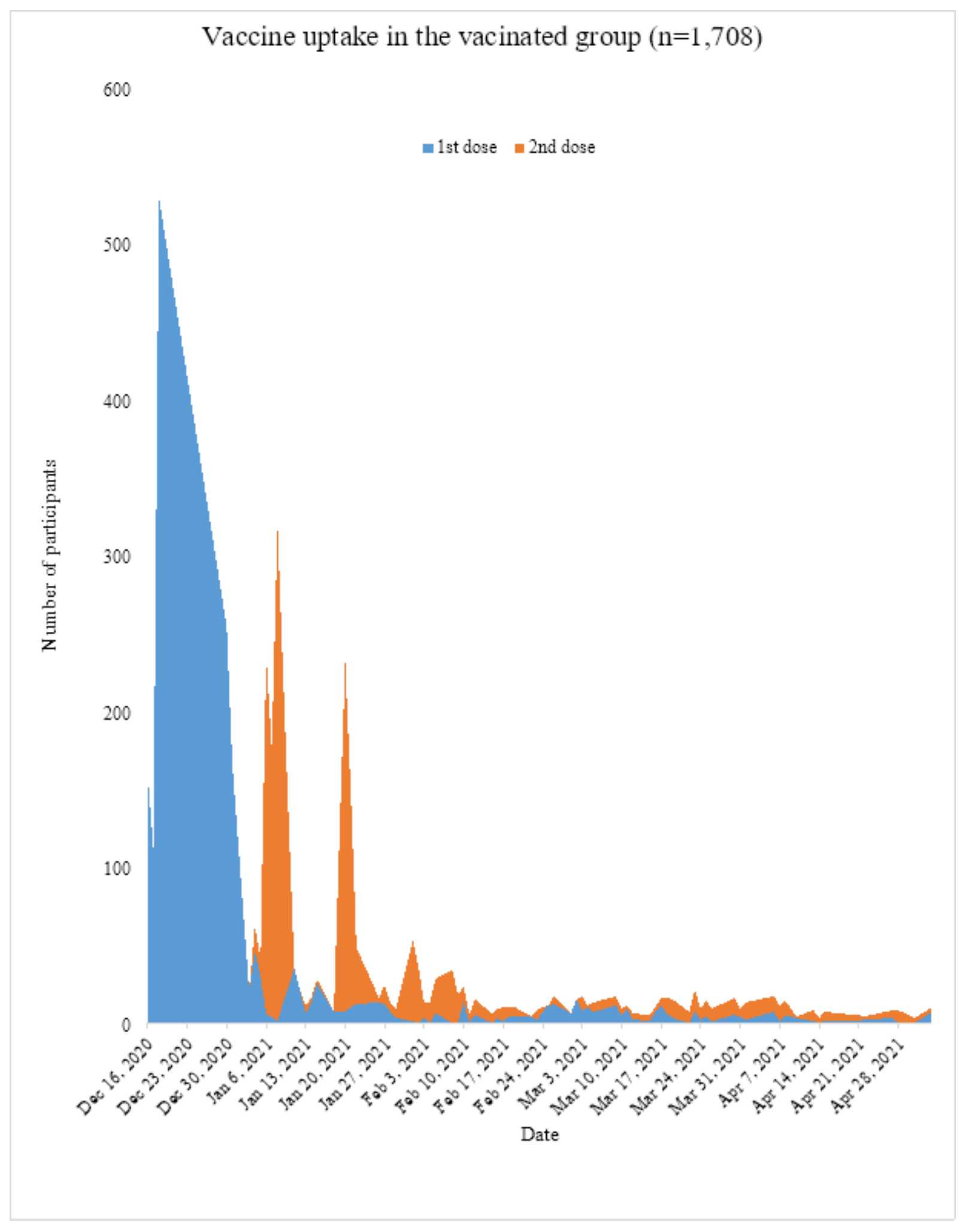

\section{Figure 2}

Number of vaccinated HCWs by first and second dose and day, Dec 16, 2020 to May 4, 2021 ( $n=1,708$; 90.97\% Pfizer/BioNTech and 9.03\% Moderna). 


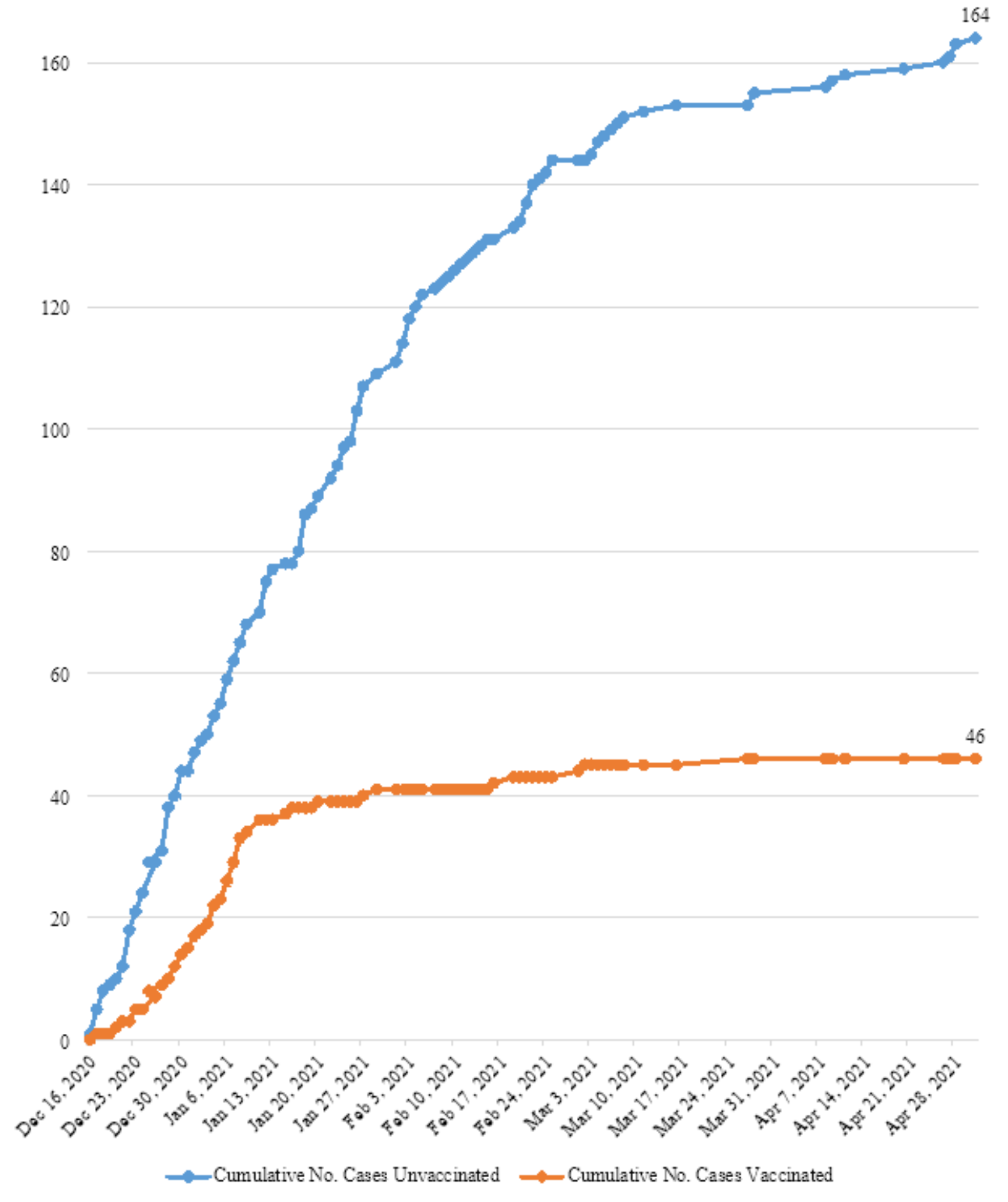

\section{Figure 3}

Cumulative daily new symptomatic SARS-CoV-2 infections in vaccinated $(n=46)$ and unvaccinated $(\mathrm{n}=164)$ participants. 